\title{
Eosinopenia as a Marker of Sepsis in Intensive Care Unit Patients
}

\author{
Suraiya Begum ${ }^{1}$, Sheuly Ferdousi ${ }^{2}$, Iqbal Hossain Chowdhury ${ }^{3}$, Mesbah Uddin Ahmed ${ }^{4 *}$, A.N. Nashimuddin Ahmed ${ }^{5}$ \\ ${ }^{1}$ Clinical Pathologist, Department of Clinical Pathology, Sir Salimullah Medical College Hospital, Dhaka. \\ ${ }^{2}$ Associate Professor, Department of Laboratory Medicine, Bangabandhu Sheikh Mujib Medical University, Dhaka. \\ ${ }^{3}$ Professor, Department of Anaesthesia, Analgesia and Intensive Care Medicine, Bangabandhu Sheikh Mujib Medical University, Dhaka. \\ ${ }^{4} \mathrm{MS}$ in Microbiology, Bangladesh University of Health Sciences. \\ ${ }^{5}$ Professor and Ex-Chairman, Department of Laboratory Medicine, Bangabandhu Sheikh Mujib Medical University, Dhaka.
}

*Corresponding Author: Mesbah Uddin Ahmed, MS in Microbiology, Bangladesh University of Health Sciences.

Received Date: 19 July 2021 | Accepted Date: 06 August 2021 | Published Date: 16 August 2021

Citation: S Begum, S Ferdousi, Iqbal H Chowdhury, Mesbah U Ahmed, A.N. N Ahmed. (2021) Eosinopenia as a Marker of Sepsis in Intensive Care Unit Patients. Journal of Clinical and Laboratory Research. 3(2); DOI:10.31579/2768-0487/038

Copyright: (C) 2021 Mesbah Uddin Ahmed. This is an open-access article distributed under the terms of the Creative Commons Attribution License, which permits unrestricted use, distribution, and reproduction in any medium, provided the original author and source are credited.

\begin{abstract}
Sepsis is one of the most common cases of mortality and morbidity in the intensive care unit (ICU). This study was done to evaluate eonsinopenia as a marker of sepsis in intensive care unit patients. This cross sectional study was carried out in the Department of Clinical Pathology, Bangabandhu Sheikh Mujib Medical University, Dhaka from March 2012 to February 2013. Absolute Eosinophil Count (AEC) was done by automated cell counter and rechecked manually microscopically. In this study 74 suspected case of sepsis were enrolled from intensive care unit, BSMMU, Dhaka. Out of these patients 34 were included in the infection group and 40 in the non-infection group depending on blood culture report. The area under ROC curve was 0.765 in current study. At the cut off valve of AEC $<40$ cell/cumm, the sensitivity and specificity of AEC for diagnosis of sepsis was $72.5 \%$ and $61.8 \%$ respectively. This present data revealed that decreased absolute eosinophil count was significantly associated with sepsis. So eosinopenia may be a reliable marker for early diagnosis of sepsis.

Key words: absolute eosinophil count (AEC); sepsis; intensive care unit (ICU); receiver operating characteristic curve (ROC)
\end{abstract}

\section{Introduction}

Sepsis is one of most common causes of mortality and morbidity in the intensive care unit (Abidi et al., 2008). Despite continuing advances in diagnosis and treatment, sepsis remains one of the important causes of higher mortality and morbidity. As the diseases progress more rapidly, the mortality rate is higher in sepsis. Early diagnosis of sepsis plays an integral role in the morbidity and mortality of patients admitted to the intensive care unit (Rey et al., 2007). Sepsis is a systemic inflammatory response to infection, manifested by two or more of the following condition as a result of infection: Temperature $>38^{0} \mathrm{c}$ or $<$ $36^{0} \mathrm{c}$, Heart rate $>90$ beats $/ \mathrm{min}$, Respiratory rate $>20$ breaths $/ \mathrm{min}$ and white cell count $>12,000 /$ cumm, $<4000 /$ cumm, or $>10 \%$ immature (band) forms (Abidi et al., 2008, Bone et al.,1992). Sepsis was documented more than $35 \%$ of patients during their ICU stay (vincent et al., 2006). The hospital mortality ranged from $16.9 \%$ for non-infected patients to $53.6 \%$ for patients who had infection at ICU. An estimated $7,50,000$ cases of sepsis occur annually in the United States and the mortality rate is about $30 \%$. The incidence will increase by 1.5 per year (Curtiset al, 2002). Normal eosinophil count is 40-400 cells/cu $\mathrm{mm}$ of blood (Firkin, 2006). Eosinopenia refers to a reduction in the normal number of circulating eosinophils (Bain, 2003). The level of eosinophils is normally tightly regulated (Abidi et al., 2008). Eosinophil production is regulated by IL-3, IL-5 and granulocyte macrophage colony stimulating factor (GM-CSF). Without these cytokines eosinophil cannot survive. These cytokines are not significantly activated in patients with sepsis. It is belived to be main mechanism of eosinopenia is sepsis (Wibrow et al., 2011). Eosinopenia during infection is also enhanced by chemotactic substance such as C5a (Shaaban et al., 2010). This substance causes migration of eosinophils into the inflammatory site (Jagadesh et al., 2012). So eosinopenia caused by migration of these cells from the vascular space, inhibition of bone marrow release and eventual decrease in marrow production (Harris et al., 1987). Sepsis and non-infectious systemic inflammatory response syndrome (SIRS) produce every similar clinical feature (Rey et al., 2007). Therapy and outcome differ greatly between patient with and those without sepsis. The widespread use of antibiotics for all such patients is likely to increase antibiotic resistance and toxicity (Gibot et al., 2004). The definitive diagnosis of sepsis is made by a positive culture, which requires a minimum of 
48-72 hours (Reimer et al., 1997). As the culture procedure is costly and longer time required, other tests in the diagnosis of sepsis are required (Vincent et al., 2010). Several markers like C-reactive protein, procalcitonin, lactate, Interleukin-1 (IL-1), Inter leukin-6 (IL-6), Tumor necroting factor (TNF) etc have been reported to predict sepsis (Shaban et al., 2010). Most of these markers are expensive and not easily accessible to clinicians. They are not ideal for early diagnosis of sepsis. Among them blood eosinophil count is simple, easy, quick, less expensive and reliable marker of sepsis (Shaabanet al., 2010, Rinaldo et al., 1999). It is part of complete blood count which is done as routine laboratory test. It can establish the presence or absence of infection and may assist clinicians regarding early administration of antibiotics. It reduces widespread use of antibiotic, mortality and sepsis related complications, the cost of treatment and shorten the hospital stay. So this study was carried out to evaluate the diagnostic sensitivity of eosinopenia for detection of sepsis in ICU patients.

\section{Materials and methods}

This cross-sectional study was conducted at the Department of Clinical Pathology in collaboration with Department of Anesthesia, Analgesia and Intensive care Medicine and Department of Microbiology and Immunology, Bangabandhu Sheikh Mujib Medical University (BSMMU), Dhaka from March 2012 to February 2013. 74 suspected sepsis patients who were admitted in the Intensive Care Unit, BSMMU, Dhaka were enrolled for the study. Study population was divided into infection and non-infection group depending on blood culture reports. 34 patients were positive for culture who were included in infection group and 40 patients were negative for culture who were included in the non-infection group. Prior to the commencement of this study, the research protocol was approved by the Institutional Review Board (IRB) of BSMMU, Dhaka. After taking written consent from patient's attendant blood sample were collected by venipuncture from each patient with all aseptic precaution. $2 \mathrm{ml}$ blood was collected from completed blood count including absolute eosinophil count. Within 2 hours CBC count including eosinophil count was done by automated cell counter and rechecked manually microscopically. Blood sample from patients who were receiving antibiotics inoculated in faster antibiotic neutralization bottles for automated blood culture and patients who were not receiving antibiotics were inoculated in conventional blood culture bottles for conventional blood culture. Single set of culture was done for each patients. All the blood culture bottles were then transported immediately to the Department of microbiology and Immunology, Bangabandhu Sheikh Mujib Medical University for further processing. Blood culture reports were collected and recorded in data sheet from report. All data were recorded systematically in a preform data collection sheet and expressed as mean \pm standard deviation (SD). Receiver operating characteristic curve and the respective are under curves was calculated for eosinophils. In a receiver operating characteristic (ROC) curve the true positive rate (Sensitivity) is plotted against the false positive rate for different cut-off points of a parameter. Each point on the ROC curve represents a sensitivity/specificity pair corresponding to a particular decision threshold. Sensitivity, specificity were calculated at the best cut off value. Statistical analysis was done by using statistical package for social science SPSS 17.0. $\mathrm{p}$ value $<0.05$ was considered as significant.

\section{Result}

In this study, 74 patients were divided into two group according to blood culture findings. Out of these patients 34 were included in the infection group and 40 in the non-infection group. The mean \pm SD of AEC was found $18.3 \pm 11.4$ cells/cu $\mathrm{mm}$ in infection group and 145.0 \pm 57.7 cells/cu $\mathrm{mm}$ in non-infection group. In infection group AEC was lower than non-infection group. The result was statistically highly significant $(\mathrm{p}<0.001)$. To evaluate the usefulness of AEC for predicting significant infection the area under the ROC curve was analyzed. The area under the ROC curve was 0.765 in current study. In receiveroperating characteristic (ROC) curve the cut-off value of AEC is $<40$ cell/cumm. At this cut-off value the sensitivity and specificity of AEC in diagnosing infection were found to be $72.5 \%$ and $61.8 \%$ respectively. These findings were statistically significant $(\mathrm{p}<0.001)$.

\begin{tabular}{|l|l|l|l|l|l|}
\hline \multirow{2}{*}{ AEC (cell/cumm) } & \multicolumn{2}{|l|}{ Infection group (n=34) } & \multicolumn{2}{|l|}{ Non infection group (n=40) } & \multirow{2}{*}{-value } \\
\cline { 2 - 5 } & $\mathbf{n}$ & $\%$ & $\mathbf{n}$ & $\%$ & \\
\hline$<40$ & 25 & 73.5 & 13 & 32.5 & \\
\hline Mean \pm SD & 9 & 26.5 & 27 & 67.5 & 0.001 \\
\hline
\end{tabular}

Table 1: Distribution of the study populations according to Absolute Eosinophil Count (AEC) (n=74)

\section{$p$ value reached from unpaired t-test}

Table 1 shows the AEC of the study patients. AEC $<40$ cells/cumm was found $25(73.5 \%)$ in infection group and $13(32.5 \%)$ in non-infection group. AEC $>40$ cells/Cumm was found $9(26.5 \%)$ in infection group and $27(67.5 \%)$ in non-infection group. The mean AEC was found $18.3 \pm 11.4$ cells/cumm in infection group and $145.0 \pm 57.7$ cells/cumm in non infection group.

The difference was statistically significant between two groups. 




Figure 1: Receiver-operating characteristic (ROC) curve of AEC for prediction of infection.

\section{Receiver-operating characteristic (ROC) curve of Absolute} Eosinophil Count (AEC) for prediction of infection

The area under the receiver-operating characteristic (ROC) curves for the infection predictors is depicted in the following table. Based on the ROC curves AEC had the best area under curve. ROC were constructed using AEC of the patients with infection, which gave a AEC cut off value of ( $<40$ cells/cu $\mathrm{mm}$ ) as the value with a best combination of sensitivity and specificity for infection. At this AEC cut-off value of $<40$ cells/cu mm, the sensitivity and specificity of AEC in infection was found to be $72.5 \%$ and $61.8 \%$, respectively. These findings were statistically significant $(\mathrm{p}<0.001)$.

\begin{tabular}{|c|c|c|c|c|c|c|c|}
\hline & \multirow{2}{*}{$\begin{array}{l}\text { Cut off } \\
\text { value }\end{array}$} & \multirow{2}{*}{ Sensitivity } & \multirow{2}{*}{ Specificity } & \multirow{2}{*}{$\begin{array}{l}\text { Area } \\
\text { under the } \\
\text { ROC } \\
\text { curve }\end{array}$} & \multirow[b]{2}{*}{ p value } & \multicolumn{2}{|c|}{$\begin{array}{l}\text { 95\% Confidence interval } \\
\text { (CI) }\end{array}$} \\
\hline & & & & & & Lower bound & Upper bound \\
\hline AEC & $<40$ & 72.5 & 61.8 & 0.765 & $0.001 \mathrm{~s}$ & 0.653 & 0.877 \\
\hline
\end{tabular}

Table 2: Receiver-operating characteristic (ROC) curve of AEC for prediction of infection

\section{Discussion}

This cross sectional study carried out to evaluated absolute eosinophil count for early diagnosis of sepsis compared with gold standard blood culture. In this study mean value of absolute eosinophil count were $18 \pm 11.4$ cells/cu $\mathrm{mm}$ in infection group and $145 \pm 57.4$ cells/ cu $\mathrm{mm}$ in no infection group. Similar findings were observed in the study done by Abidi et al (2008), Shaban et al (2010), Kadir et al (2012), Gil et al (2003). From the study of Kadir et (2012) mean absolute eosinophil count were $23 \pm 46$ cells/ cu $\mathrm{mm}$ in sepsis and $143 \pm 101$ cells/ cu mm in patients without sepsis. This finding was similar to our study. In previous study the sensitivity of eosinopenia in sepsis patient had a resonable range of variation. Our study showed sensitivity $75.5 \%$ which was consistent with the study of Abdi et al (2008). From the study of Abidi et al (2008), Bayram el al (2012), Lopez et al (2010), Gil et al (2003), sensitivity was $71 \%, 61.4 \%, 64.8 \%, 64 \%$ respectively. These result were nearly consistent with our study. The present study has also defined the specificity of eosinopenia in sepsis patients. Our study showed specificity of eosinopenia for diagnosis of sepsis was $61.8 \%$ which was consistent with the study of Shaban et al (2010). According to their observation specificity was $65 \%$. From the study of Lopez et al (2010), Moura et al (2011) specificity was 70.9\%, 71\% respectively. These results were nearly consistent with our study. The area under ROC curve for the sepsis was depicted in our study. The area under receiver operating characteristic curve was 0.765 in current study. This is similar to the observation of the study done by Shaban et al (2010). According to their observation the area under receiver operating characteristic curvy was 0.72 which is consistent with our study. Considering the sensitivity specificity, this study implies that eosinopenia is reliable as a diagnostic tool for sepsis. The level of eosinophils in the body is normally tightly regulated (Abidi et al., 2008). Eosinophil production is requlated by IL-3, IL-5 and granulocyte macrophage colony stimulating factor. Without these cytokines, eosinophil cannot survive. These cytokines are not significantly activated in patients with sepsis. It is believed to be main mechanism of eosinopenia in sepsis (Wibrow et al.). Eosinopenia during infecton is also enhanced by chemotactic substance such as c5a (Abidi et al., 2008, Shaabon et al., 2010). Eosinopenia may be the result of migration of eosinophils into the inflammatory site itself due to release of the chemotactic factor of acute inflammation in to the circulation (Jagadesh et al., 2012). So eosinopenia caused by migration of these cells from the vascular space, inhibition of bone marrow release and eventual decrease in marrow production (Harris et al., 1987).

\section{Conclusion}

Form this study, it can be concluded that AEC is significantly lower in patients with sepsis. Eocinopenia may be a useful marker to 
distinguish the infected from non-infected patients. An early diagnosis of sepsis is made by absolute eosinophil count that can be obtained from routine laboratory test (Complete bood Count) which is simple, quick, cost effective and readily available. In our study eosinopenia provide an effective guideline to make decision regarding judicious use of antibiotic therapy which will be lifes aving and minimize the risk of emergence of resistant organism due to misuse of antibiotics.

\section{References}

1. Abidi K, Khoudri I, Belayachi - J, Madani N, Zekraoui A, Zeggwagh AA, Abouqal R. ( 2008). 'Eosinopenia is a reliable markers of sepsis on admission to medical intensive care unit', Critical Care. 12; 1-10.

2. Abidi K, Khoudri I, Belayachi J, Derras Y, Khayari ME, Madani N, Zeggwagh AA, Abouqal R (2011). 'Eosinopenia, an early marker of increased mortality in critically ill patients', Intensive Care Med. 37; 113-1142.

3. Bain BJ. (2003). 'Assessing White Cells and Platelets' In A beginner's guide to blood cells, Blackwell Publishing, Available from: Blood Med.

4. Bayram N, Kaya A, Ami N, \$ahbudak B, Sen S. Helvac M. (2012). 'Diagnostic value of eosinopenia in children with bacterial infection',Electronic libray.

5. Bone RC, Balk RA, Cerra FB, Dellinger RP, Fein AM, Knaus WA, Schein RM, Sibbald WJ. (1992). 'American College of Chest Physicians/ Society of Critical Care Medicine Consensus Conference: definition for sepsis and organ failure and guidelines for the use of innovative therapies in sepsis', Chest. 101; 1644-1655.

6. Curtis NS, Wes S. (2002). 'New concepts in sepsis', Current Opinion in Critical Care. 8; 465- 472.

7. Firkin F, Chesterman C, Penington D, Rush B. (2006). 'White cells', In de Gruchy's, Clinical Haematology in Medical Practice, 5th edition, Blackwell Science, Oxford. 216-220.

8. Gibot S, Kolopp-Sarda MN, Bene MC, Cravoisy A, Levy B, Faure GC, Bollaert PE. (2004). 'Plasma level of a triggering receptor expressed on myeloid cells-1: its diagnostic accuracy in patients with suspected sepsis', Ann Intern Med. 141; 9-15.
9. Gil H, Magy N, Mauny F, Dupond JL. ( 2003). 'Value of eosinopenia in inflammatory disorders: an 'old' marker revisited', Rev Med Interne. 24; 431·A35.

10. Harris RL, Daniel M, Kim B, Gathe, Lawrence,BS, Temple W, Edward J. (1987). 'Manifestations of sepsis', Arch Intern Med. 147; 895-1906.

11. Jagdeesh TS, Mishra A, Saxena A, Sharma D. ( 2012). 'Eosinopenia as a prognostic marker in patients with peritonitis', INSR Infectious diseases. 1-8.

12. Kadir NA, Arif M, Bahrun U. (2012). 'Eosinophil as a marker to distinguish sepsis from systemic inflammatory response syndrome (SIRS) patients in intensive care unit', $15^{\text {th }}$ ICID; 55.002.

13. Lopez TMC, Sanchez CM, Rodriguez VS, Raigal CA, Reina TP, Velasco RA. (2010). 'Evaluation of eosinopenia an an infection marker in critical care patients. Med Intensiva. 34 (4); 246-253.

14. Moura EB, Maia MO, Neto JAA, Amorim FF. (2011). 'Relevance of eosinopenia as an early sepsis marker', Crit Care. $15(1) ; 20$.

15. Reimer LG, Wilson ML, Weinstein MP. ( 1997). 'Update on detection of bacteremia and fungemia', Clin. Microbiol. 10; 444-465.

16. Remick C, Arcos ML, Concha A, Medina A, Prieto S, Martinez P, Prieto B. (2007). Procalcitonin and CRP as markers of systemic inflammatory response syndrome severity in critically ill children', Intensive Care Med. 33; 477-484.

17. Shaaban H, Daniel S, Sison R, Slim J, Perez G. (2010). Eosinopenia: Is it a good marker of sepsis in comparison to procalcitonin and C-reactive protein levels for patients admitted to a critical care unit in an urban hospital', Journal of Cri tical Care. 25; 570-575.

18. Vincent JL, Sakr V, Sprurg CL, Ranicri VM, Payen D. (2006). 'Sepsis in European intensive care unit., Results of the SOAP study', Crit Care Med. 34; 344-353.

19. Wibrow BA, Ho KM. Flexman JP, Keil AD, Kohrs DL. (2011). 'Eosinopenia as a diagnostic marker blood stream infection in hospitalized paediatric and adult patients: a case control study', Anaesthesia and Intensive care. 0310-057x.

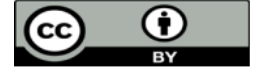

This work is licensed under Creative Commons Attribution 4.0 License

To Submit Your Article Click Here: Submit Article
Ready to submit your research? Choose Auctores and benefit from:

* fast, convenient online submission
* rigorous peer review by experienced research in your field
*apid publication on acceptance
* uuthors retain copyrights
* imique DOI for all articles
immediate, unrestricted online access

At Auctores, research is always in progress.

Learn more www.auctoresonline.org/journals/journal-of-clinical-andlaboratory-research 